\title{
Dr. Christian Moreau Inducted into the 2013 Thermal Spray Society Hall of Fame
}

The Thermal Spray Hall of Fame recognizes outstanding leaders who have made significant contributions to the science, practice, education, management, and advancement of thermal spray. Dr. Christian Moreau, FASM, and the Editorin-Chief of Journal of Thermal Spray Technology since 2004, was inducted into the Thermal Spray Hall of Fame on May 13, 2013 at the International Thermal Spray Conference in Busan, South Korea.

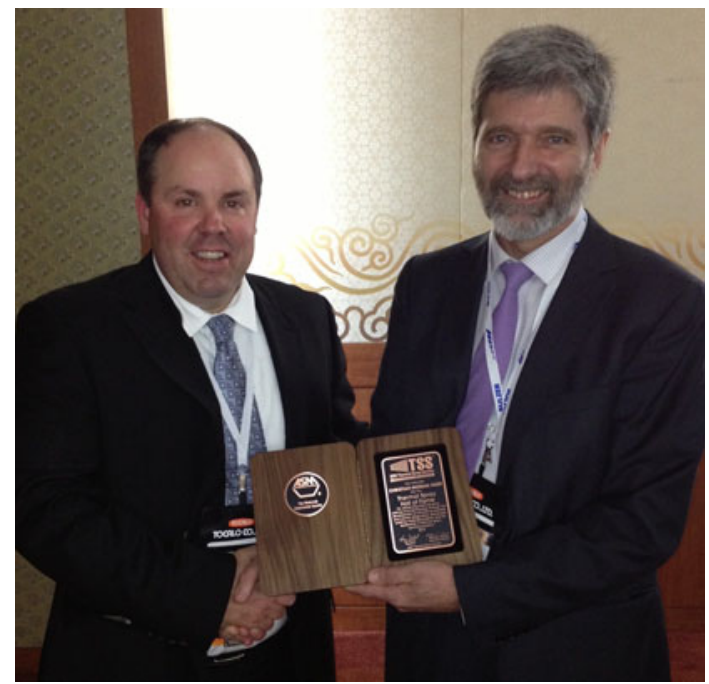

Dr. Christian Moreau (right) accepts the Thermal Spray Hall of Fame plaque from Mr. Luc Pouliot (left), Chief Operating Officer of Tecnar Automation Limited, at the International Thermal Spray Conference in Busan, South Korea, in May 2013.

Dr. Moreau's award citation reads as follows: "For advancing thermal spray science and technology through the development of innovative scientific and control diagnostics, advanced coating materials systems, and for leadership in thermal spray communications."

He was selected based on both his personal contributions to thermal spray technology, as demonstrated by his seven patents and many publications, as well as for his management of an internationally recognized research organization. He has advanced the understanding and development of thermal spray technology through his significant role in the development of optical systems for the measurement of the plasma effluent and particle temperature, velocity, and their distributions.

Dr. Moreau has been an active member of the Thermal Spray Society and ASM International. He has served on the Thermal Spray Society Advisory Council from 2011 to 2013, the TSS Nominating Committee from 2010 to 2012, and has been a member of both TSS Publications and Communications as well as the TSS Program Committee from 1999 to 2013. He was a TSS Board Member from 2006 to 2012 and was also a member of TSS Information Development/Delivery. In addition, his ASM contributions include being a member of the ASM Nominating Committee in 2009 and serving on the ASM New Products and Services Committee. He became an ASM Fellow in 2006. He is presently the Editor-in-Chief of the Journal of Thermal Spray Technology and has been a member of the JTST Committee since 1999.

Along with Dr. Moreau, Dr. Brad Beardsley of Caterpillar, Inc. was also inducted into the TSS Hall of Fame during ITSC. Dr. Beardsley's citation reads as follows: "For advancing thermal spray science and technology through the development of innovative scientific and control diagnostics, advanced coating materials systems, and for leadership in thermal spray communications." 